\title{
Migraine: The Doctor-Patient Link. Results of a Needs Assessment
}

\author{
R. Allan Purdy
}

\begin{abstract}
Objectives: To do a needs assessment directed to neurologists attending a workshop on communication skills emphasizing relationships between physician and patient, assessment of disability and quality of life of migraine patients, and communication of therapies for migraine. Methods: A structured questionnaire was sent to all participants related to the issues indicated in the objective. This was prepared by the faculty and the results were collated by the author and presented at the beginning of the workshop. This paper overviews the use and results of a needs assessment to highlight learning needs of the participants and to focus the issues, interest and interactions of neurologists in a workshop. The workshop focused primarily on communication skills and on the understanding of disability and quality of life issues in migraine patients. Results: In general the responses revealed that the attendees were neurologists in practice for more than 15 years, that over 50\% had prior knowledge of communication skills and used them in various ways, and $74 \%$ were involved in teaching family physicians. Some knew and used disability and quality of life tools but up to one third of participants did not assess disability in their patients. Most wanted to learn more about communication skills and other objectives noted and $19 \%$ of respondents wanted to learn more about prophylactic antimigraine treatments and how to differentiate/contrast the triptans. Conclusion: Using a needs assessment tool allowed organizers of an educational workshop to determine the current knowledge and perceived and unperceived needs of the participants with respect to communication skills, assessing disability and quality of life issues, and communication of treatments to migraine patients.
\end{abstract}

RÉSUMÉ: La migraine: le lien médecin-patient. Résultats d'une évaluation des besoins. Objectifs: Faire une évaluation des besoins auprès de neurologues participant à un atelier sur les aptitudes à communiquer, en mettant l'emphase sur les relations entre le médecin et le patient, sur l'évaluation de l'invalidité et de la qualité de vie des patients migraineux et sur la communication de l'information sur les thérapies de la migraine. Méthodes: Un questionnaire structuré sur les sujets indiqués dans l'objectif a été envoyé à tous les participants. Ce questionnaire avait été préparé par les chargés de formation et les résultats ont été compilés par l'auteur et présentés au début de l'atelier. Cet article donne un aperçu de l'utilisation d'une évaluation des besoins et des résultats de cette évaluation pour souligner les besoins des participants en termes d'apprentissage et pour préciser les questions, l'intérêt et les interactions des neurologues pendant l'atelier. L'atelier ciblait avant tout les aptitudes à communiquer et la compréhension des problèmes concernant l'invalidité et la qualité de vie chez les patients migraineux. Résultats: Les participants étaient des neurologues en pratique depuis plus de 15 ans, plus de $50 \%$ avaient des connaissances sur les aptitudes à communiquer et les utilisaient de différentes façons, et $74 \%$ faisaient de l'enseignement aux médecins généralistes. Certains connaissaient et utilisaient des outils pour évaluer l'invalidité et la qualité de vie, mais plus du tiers des participants n'évaluaient pas l'invalidité chez leurs patients. La plupart désiraient en savoir davantage sur les aptitudes à communiquer et sur les autres objectifs mentionnés et $19 \%$ des répondants désiraient avoir de l'information sur les traitements prophylactiques antimigraineux et sur les caractéristiques des différents triptans. Conclusion: L'utilisation d'un outil d'évaluation des besoins a permis aux organisateurs d'un atelier éducatif de déterminer les connaissances et les besoins perçus et non perçus des participants quant aux aptitudes à communiquer, à l'évaluation des problèmes d'invalidité et de qualité de vie, et à la communication aux patients migraineux d'informations sur les traitements.

Can. J. Neurol. Sci. 2002; 29: Suppl. 2 - S3-S7

A primary goal of continuing medical education (CME) is to enhance the learners' performance. Doing an appropriate needs assessment is an important prerequisite to any education workshop. A major goal of any educational workshop is to ensure that the participants learn what they need to know about communication skills the subjects presented based both on their own perceived needs and on those that they do not perceive.

Needs assessments ${ }^{1}$ are part of CME programs and have played a role in allowing planning committees not only to specify what should be taught, but also allowing the planners to learn the perceived needs of the participants. A recent needs assessment of Canadian neurologists revealed that neurologists had a primary interest in new therapeutic treatments for migraine, and not diagnostic, investigative or other management issues related to headache and migraine. ${ }^{2}$ That needs assessment, however, did not question whether the neurologists would want to know more about communication skills relating to migraine patients or disability or quality of life issues in such patients.

In mid-2000 the Canadian Headache Society decided to sponsor a workshop for neurologists on communications skills and on disability and quality of life assessments in order to

From the Division of Neurology, Dalhousie University and Queen Elizabeth II Health Sciences Centre, Halifax, Nova Scotia, Canada

Reprint requests to: RA Purdy, Division of Neurology, Dalhousie University and

Queen Elizabeth II Health Sciences Centre, 1796 Summer Street, Halifax, Nova Scotia B3H 3A7 Canada 
enhance their interactions with migraine patients and to communicate about appropriate therapies. In preparation for this workshop, a questionnaire was sent to potential participants to determine their knowledge and potential learning needs in the areas of concern. The workshop, "Migraine: The Doctor-Patient Link" was held in Toronto in February 2001.

Communication skills have been for a decade, and continue to be, an important part of undergraduate medical curricula. ${ }^{3,4}$ Further, it is recognized that patients want more than just medications when they consult a physician regarding their headaches. ${ }^{5}$ Tools have been developed to assess the disability and quality of life of migraine patients. Although primarily employed in headache research, for example as part of randomised clinical trials, more recent validated tools are becoming useful in practice as well. ${ }^{6,7}$ It is helpful if neurologists know how to best communicate the right therapies to the right patients at the right time, and the workshop included a casebased session to allow them to practice these skills. All of these areas were covered in the workshop and are dealt with in greater detail in other papers in this supplement. It was hoped that the participants would learn to use these skills to better manage their migraine patients in their practices.

The demographic data and needs assessment of neurologists who participated in the communication workshop is described in this paper. The data collected for the needs assessment allowed for an on site review of the results and needs. This in turn focused the faculty and participants on relevant learning issues regarding communications skills and disability/quality of life issues related to interactions with migraine patients.

\section{METHODS}

A questionnaire was developed by the faculty and was mailed out to all potential participants of the workshop. The questionnaire consisted of twenty questions, five of which were designed to understand the demographics of the participants and their prior involvement in communications skills with patients and other learners. The other fifteen questions specifically dealt with diagnostic, communication skills and disability/quality of

\section{Table 1: Demographics}

Question A1. In which province do you practice?

(\% of 43 respondents)

$\begin{array}{lllllll}\mathrm{BC} & \mathrm{AB} & \mathrm{SK} & \mathrm{MB} & \mathrm{QC} & \mathrm{ON} & \text { Atlantic } \\ 7 & 5 & 9 & 7 & 21 & 35 & 16\end{array}$

Question A2. How many years have you been in practice? (\% of 43 respondents)

$\begin{array}{cccc}<5 \text { years } & 5-10 \text { years } & 11-15 \text { years } & >15 \text { years } \\ 17 & 26 & 17 & 40\end{array}$

Question A3. In what type of setting do you treat migraine patients? (\% of 43 respondents) Academic/university-based setting $\quad 12$ University-affiliated setting 23 Community-based practice $\quad 60$ Other life assessments in migraine patients, to determine the level of knowledge and preferences of the participants.

Of 50 questionnaires sent to potential participants that attended the workshop, 43 neurologists responded to the questionnaire for a response rate of $86 \%$. The data from the questionnaires were collated, analyzed and produced in graphic,

Table 2. Communication Training and Teaching

Questions A4. Have you received formal communication skills training as a medical student, resident or practising physician?

Yes $\quad 54 \%$

No $\quad 46 \%$

If yes, please estimate how many hours/days:

- 3 hours/week x 10 weeks

- throughout medical school

- 2 days

- 4 days

- unable to determine

- 20 hours

- 1 day, a few hours/session

- 1-3 days

- 1 hour/week

- 6 hours/week

- parts of MBAprogram

- 60 hours

- 50 hours

Question A5. Are you currently engaged in teaching any of the following? (\% of 43 respondents)

Medical students $\quad 51$

Residents 51

Family physicians $\quad 74$

Specialists $\quad 16$

Other 9

If yes, what is the nature of your involvement, including whether you teach physician-patient communication?

- Do not teach communication skills. Most teaching to students/residents is clinical. Family practitioners, other specialists is by seminars and talks.

- Continuing medical education sessions

- Case-based learning

- Clinical skills to medical students and clinical lectures to MDs

- Local continuing medical education for family physicians

- Preceptor for nurse educator trainee

- Pediatric neurology, not communication

- Clinical neurology

- Clinical skills

- Hospital rounds

- Teaching and training OPD

- Simulated patients videotaped interviews

- Faculty

- Course on headaches; fundamentals of communication techniques

- Produce self-training module

- Speaking to media 
Table 3: Migraine Diagnosis and Management

Question B1. I think the most important aspect of the diagnosis and management of migraine patients is: (\% of 43 respondents)

Accurate history

23

Patient education

Making diagnosis and reassuring the patient

Appropriate treatment

Good communication between patient and physician

Pain management

Empower patient to be in control

Knowledge

Medical exam

Prophylactic measures

More compassion for patient

Create trusting environment

Question B2. I think the main reason patients may be dissatisfied with medical care of their migraines is: (\% of 43 respondents)

Adequate understanding of condition 9

Poor communication and understanding of the disease $\quad 35$

$\begin{array}{ll}\text { Lack of sympathetic ear } & 19\end{array}$

Failure of prophylactic treatment $\quad 17$

Inappropriate therapy 14

Poor relief of headaches

Lack of medication efficacy

Too much emphasis on drug
Question B5(a). Are you familiar with the Headache Impact Test (HIT)?

$\begin{array}{ll}\text { Yes } & 30 \% \\ \text { No } & 70 \%\end{array}$

Question B5(b). Do you use this tool in your practice?

Yes $\quad 5 \%$

No $\quad 95 \%$

Question B6(a). Are you familiar with the Migraine Disability

Assessment (MIDAS) tool?

Yes $\quad 81 \%$

No $\quad 19 \%$

Question B6(b). Do you use this tool in your practice?

Yes $\quad 33 \%$

No $\quad 67 \%$

If yes, briefly describe how:

- Blended model

- Patients complete this indirectly

- My questionnaire includes question about disability

- During the interview

- Discussed with patient after they fill it out

- At first visit

- Occasionally, but partial evaluation

Question B7. Does/would a patient's level of disability affect your choice of migraine treatment?

Yes $\quad 95 \%$

No $\quad 5 \%$

If yes, briefly describe how:

- If disabled by a headache go straight to a triptan

- More disabilities > more aggressive

- It influences prophylaxis

- Pediatric - sumatriptan nasal for those with severe attacks

- If very mild - analgesics

- Affects the impact of treatment strategies

- Aggressive approach

- More disability - follow-up

- Would eliminate trigger factors

Question B8. Do you consider aspects of the way you communicate with migraine headache patients to be a part of the treatment/management plan?

Yes $\quad 90 \%$

No $\quad 10 \%$

If yes, please describe:

- Lifestyle management issues

- Education of meds and treatment is first step

- Relaxed communication between doctor and patient, empathise

- Acceptance/adequate work up

- Good interviewing techniques

- Written list of topics for them to take with them

- Simple words and examples

- Open-ended questioning

- Discussion and planning with patient

- Telephone calls 
Table 5: Disability, Quality of Life and Patient Education

Question B9. In your opinion, how does disability assessment rank in terms of priority when assessing a new or repeat patient? (\% of respondents)

$\begin{array}{llllllll}\text { Least important } & 0 & 0 & 9 & 33 & 47 & 12 & \text { Most important }\end{array}$

Question B10. In your opinion, how does quality of life rank in terms of priority when assessing a new or repeat patient? (\% of respondents) $\begin{array}{llllllll}\text { Least important } & 0 & 0 & 0 & 30 & 58 & 12 & \text { Most important }\end{array}$

Question B11. In your opinion, how effective is patient education in enabling migraine patients to manage disability?

$\begin{array}{llllllll}\text { Least important } & 0 & 0 & 2 & 26 & 40 & 33 & \text { Most important }\end{array}$

Table 6: Compliance with Medications

Question B12. I think the THREE most important reasons patients are not compliant with migraine medications are: (\% of respondents)

Lack of understanding/fear

37

Poor communication

39

Failed therapies

Depression

Inconvenience

Side effects

Cost

Unreasonable expectations

Medication ineffective

Psychological factors relating to pain

Lack of motivation

Wrong medications

text and tabular form. The author presented the results of the assessment at the beginning of the workshop. As in a prior presentation of a similar nature, ${ }^{8}$, the learning needs and knowledge assessment results for this workshop set the stage for the didactic sessions that followed, and for the communication skills interactive case based small group sessions. This was found to be an effective strategy to facilitate learning and to highlight the important issues of this educational event.

\section{RESUltS}

The complete needs assessment and questionnaire and responses are shown in Tables 1-7.

\section{Discussion}

It is interesting to analyze, in general terms, the results of the responses to the questions. (It should be noted that this assessment tool was not pretested before the workshop, nor was there a testing of its reliability, and thus the findings may not be able to be generalized to other groups).
Table 7: Expectations of the Workshop

Question B13. What aspect of communicating with patients would you like to enhance at this meeting? (\% of respondents)

Shorten time it takes to communicate by messages 2

Enhance communication skills 33

Education $\quad 14$

Simple visual images of migraine pathophysiology 2

Techniques 5

How to explain what a rebound headache is 2

$\begin{array}{ll}\text { How to deal with chronic pain issues } & 10\end{array}$

Feedback on outcome of treatment attempts 5

$\begin{array}{lr}\text { Psychotherapy } & 10\end{array}$

Getting a short history $\quad 2$

Retrieval of data $\quad 2$

How to explain limitations of explanations 2

Make patient accountable $\quad 2$

Question B14. What ONE aspect of physician-migraine patient communication would you like to see addressed in this workshop? (\% of respondents)

What is the most effective strategy 2

Education of patient $\quad 12$

Assessment tools 5

Optimise use of "HIT"

Setting realistic 2

Medication compliance $\quad 5$

Management 9

How to address patient concerns $\quad 7$

MIDAS tool 2

Proper dose of triptans $\quad 2$

Trust 2

Question B15. What ONE other aspect of migraine care would you like to see addressed in this workshop? (\% of respondents)

Maximising effective communication 2

New prophylactic medications $\quad 12$

How to deal with withdrawal of analgesics 2

Women in migraine $\quad 2$

Lifestyle modification $\quad 2$

Appropriate follow-up $\quad 2$

Enhanced specialist (to patient) to family physician teaching with each case 2

How to explain nature of migraines 5

How to improve cost of medication to patient 2

Difference/contrast of triptans $\quad 7$

Chronic daily headache 2

Pathophysiology of migraine 2

Transformed migraine (analgesic abuse) 2

Web site for patients $\quad 2$

Supporting information for patients $\quad 2$ 
The demographic data on the participants indicated that the majority were community based neurologists and that most had been in practice for greater than ten years (Table 1). Further, about half indicated that they had had some communication skills training but, if analyzed carefully, the experiences were usually brief and highly variable (Table 2). Most clinicians in practice for 15 years or longer probably were not exposed to formal communication skills teaching in medical school.

Importantly, the results indicated that the participants of the workshop were in a position to influence many learners across the medical education continuum, particularly medical students and family physicians (Table 2). As family physicians see large numbers of patients with headache it would be expected that the workshop participants would then be able to teach them some new skills they learned at the workshop. However, some of the "communications skills" indicated in the response in the needs assessment under Question A5 would not be viewed as those taught in present medical school curricula. ${ }^{3,4}$ Nevertheless, it was hoped that the workshop would allow the participants to learn these newer skills and convey them to their family practice colleagues.

The next fifteen questions (Tables 3-5) deal with diagnostic, communication skills and disability/quality of life assessments in migraine patients. Most of the responses were as expected by the faculty with a clear recognition by the participants of the need for good communications skills training and a desire to learn communications skills. This validated the need for the workshop. Most participants indicated that patient education was a significant part of the doctor-patient link and this was a consistent theme in the answers given to the questions.

As for disability assessments, most agreed that such assessments were important but most did not routinely use a recently-developed, well-known disability scale $^{6}$ in their assessments, and few had knowledge of a new scale ${ }^{7}$ available to patients on the Internet. These new scales have both been validated and do enhance the ability of the patient to make a quantitative assessment of their own disabilities. The first scale, the Migraine Disability Assessment (MIDAS) scale, ${ }^{6}$ is based on non-pain or disease parameters but utilizes days of loss of function to quantitate disability. It thus can be used as a comparator at various visits to see the progress of the patient or not. In the Headache Impact Test (HIT) scale $^{7}$ done online, the patient answers questions that allows a quantitation of factors that determine the need to see a physician and seek therapy. Longitudinal use of HIT allows a quantitation of illness and disability.

It was also clear that most participants used various other methods to assess disability and quality of life issues, most of which were not quantitative or validated in the literature as were MIDAS and HIT. The desire to learn about these areas was clearly emphasized in the participants' answers but their knowledge in these areas was lacking and they appeared not to want to learn about the quantitative scales, with only $2 \%$ wishing to learn more about MIDAS and the same percentage about HIT. This once again highlighted the need for the workshop, as it appeared to the organizers that patients and family physicians may find MIDAS and HIT to be useful tools.

One surprising outcome of the needs assessment was the desire of the participants to know more about new prophylactic medications for use in migraine patients. This is understandable to some extent since most educational courses related to migraine therapy in the past decade have dealt with the newer abortive agents for migraine, and there is a need to find new effective prophylactic agents. This knowledge need was identified and was addressed in the author's presentation. To some extent it was also dealt with in one of the plenary sessions of the workshop in that current prophylactic medications were discussed but new agents were not overly emphasized.

\section{CONCLUSION}

Using a needs and knowledge assessment tool to collect data in order to conduct an on-site review of the responses before a CME workshop has merit, especially since the data were presented and discussed with the participants and faculty before the workshop began. This data highlighted and gave focus to the learning needs of the participants and acted as a learning tool as well as a knowledge evaluation tool. Pretest and post-test evaluation tools are used commonly in CME. This tool collected precourse demographic, knowledge, needs and participant preference data, and contained many of the elements of a formal needs assessment.

The information gathered and discussed in this paper was of a semiquantitative and qualitative nature, and this was the intention of the workshop planners. The preworkshop use of this information appeared to enhance the learner's interest, interactions, enthusiasm and knowledge in a positive fashion prior to the actual workshop. The workshop was designed to educate the participants in the areas highlighted by the assessment tool. Importantly, the use of an educational tool, such as a needs assessment, hopefully maximized the learning of the participants to better manage their migraine patients.

\section{REFERENCES}

1 Rosof AB, Felch WC. (Eds.) Continuing Medical Education: A Primer. Second ed. Westport, Connecticut: Praeger. 1992.

2. Morris B, Suchowersky O, Freedman M, et al. Learning needs of Canadian neurologists. Ann R Coll Phys Surg Can 1999;32:8792.

3. Essential Elements of Communication in Medical Encounters: The Kalamazoo Consensus Statement. Acad Med 2001;76(4):390393.

4. Makoul G, Schofield T. Communication teaching and assessment in medical education: an international consensus statement. Patient Educ Couns 1999;137:191-195.

5. Packard RC. What does the headache patient want? Headache 1989;29:370-374.

6. Stewart WF, Lipton RB, et al. Developing and testing of the Migraine Disability Assessment (MIDAS) Questionnaire to assess headache-related disability. Neurology 2001; 56(6 Suppl 1):S20-28

7. Kosinski M, Bjorner JB, Bayliss MS, Ware JE. Measuring the impact of migraine and severe headache with the headache impact test: using item response theory (IRT) models to score widely-used measures of headache impact and assess disability due to migraine or other severe headaches. Neurology 2000;54:S71.004.

8. Purdy RA. Evidence-based migraine therapy: learning needs and knowledge assessment. Cephalalgia 2000;20(Suppl 2):5-9. 